\title{
Magnetic resonance imaging of sternoclavicular joint arthritis due to SAPHO syndrome
}

\author{
Kiyoshi Shikino, Masatomi Ikusaka, Yusuke Hirota
}

\section{CASE REPORT}

A 55-year-old male had been experiencing pain over the left shoulder to the anterior part of the chest since two days. Physical examination indicated a body temperature of $37.8^{\circ} \mathrm{C}$, as well as swelling, elevated temperature, and tenderness on the left side of the sternum (Figure 1). The pain worsened with elevation of the left shoulder, right rotation and retroflexion of the neck, and deep inspiration. Blood tests showed an inflammatory response (C-reactive protein, $13.1 \mathrm{mg} / \mathrm{dL}$, erythrocyte sedimentation rate, $48 \mathrm{~mm} / \mathrm{h}$ ). Rheumatoid factor and anti-cyclic citrullinated peptide (anti-CCP) antibody were negative. Joint aspiration was not performed because ultrasonography did not detect the effusion of sternoclavicular joints. Computed tomography (CT) scan of the sternoclavicular joints revealed an erosive change in the left sternoclavicular joint. Magnetic resonance with the short-T1 inversion-recovery (MR-STIR) sequence showed an abnormal signal in the left sternoclavicular joint (Figure 2). A non-steroidal anti-inflammatory drug was orally administered, and the symptoms disappeared after one month. Although no skin eruption developed during the follow-up, sternoclavicular joint arthritis due to SAPHO syndrome was diagnosed.

Kiyoshi Shikino ${ }^{1}$, Masatomi Ikusaka ${ }^{2}$, Yusuke Hirota ${ }^{3}$ Affiliations: ${ }^{1} \mathrm{MD}$, Project Assistant Professor, Department of General Medicine, Chiba University Hospital, ChibaCity, Japan; ${ }^{2} \mathrm{MD}$, Ph.D, Professor, Department of General Medicine, Chiba University Hospital, Chiba- City, Japan; ${ }^{3} \mathrm{MD}$, Intern Doctor, Department of General Medicine, Chiba University Hospital, Chiba- City, Japan.

Corresponding Author: Kiyoshi Shikino, Chiba- city, Chiba, Japan 260-8560; Ph: +81-43-222-7171 (Ext. 6438); +81-43224-4758 (Direct Line) +81-43-224-4758; Email: kshikino@ gmail.com

Received: 01 March 2014

Accepted: 01 April 2014

Published: 01 June 2014

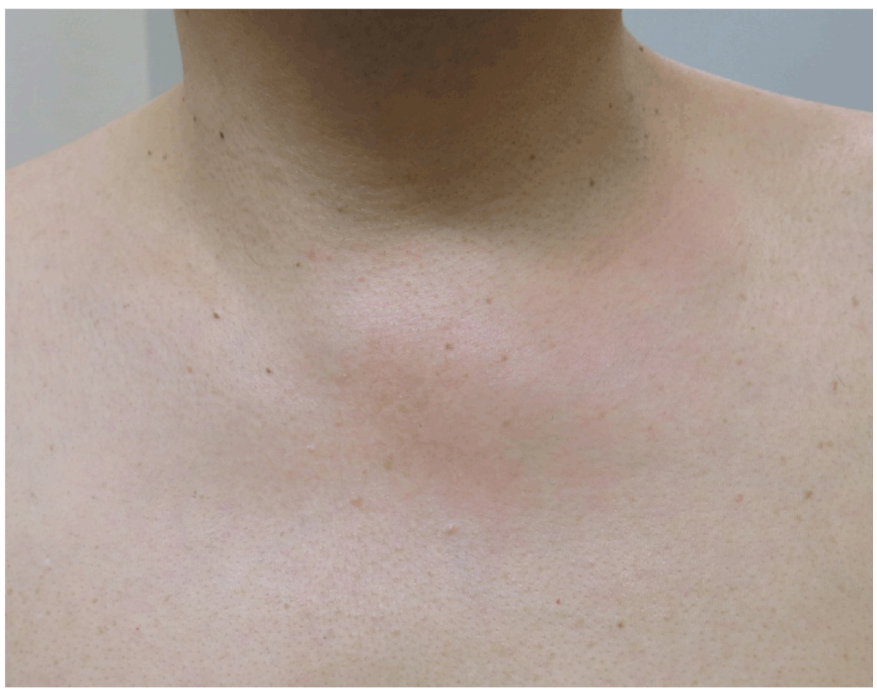

Figure 1: Swelling on the left side of the sternum.

\section{DISCUSSION}

Conditions of the sternoclavicular joints are sometimes misdiagnosed as shoulder diseases because sternoclavicular joints are involved during shoulder joint elevation. When inflammation related to sternoclavicular joint arthritis spreads to the sternocleidomastoid muscles, retroflexion of the neck or rotation to the unaffected side causes pain. Sternoclavicular joint arthritis may be caused by septic arthritis, osteoarthritis, rheumatoid arthritis, SAPHO syndrome, ankylosing spondylitis, psoriasis, gout, or pseudogout [1]. Among those, erosive changes of in sternoclavicular joints have been observed in rheumatoid arthritis, ankylosing spondylitis, psoriasis and SAPHO syndrome. Anti-CCP antibody was negative in this patient, making rheumatoid arthritis unlikely. Ankylosing spondylitis typically develops in young adults and occurs insidiously. Nail lesions and dactylitis were not observed, making psoriatic arthritis unlikely. Among patients with SAPHO syndrome, 65-90\% experience damage in the bones and joints of the anterior chest. Skin symptoms such as severe acne and palmoplantar 

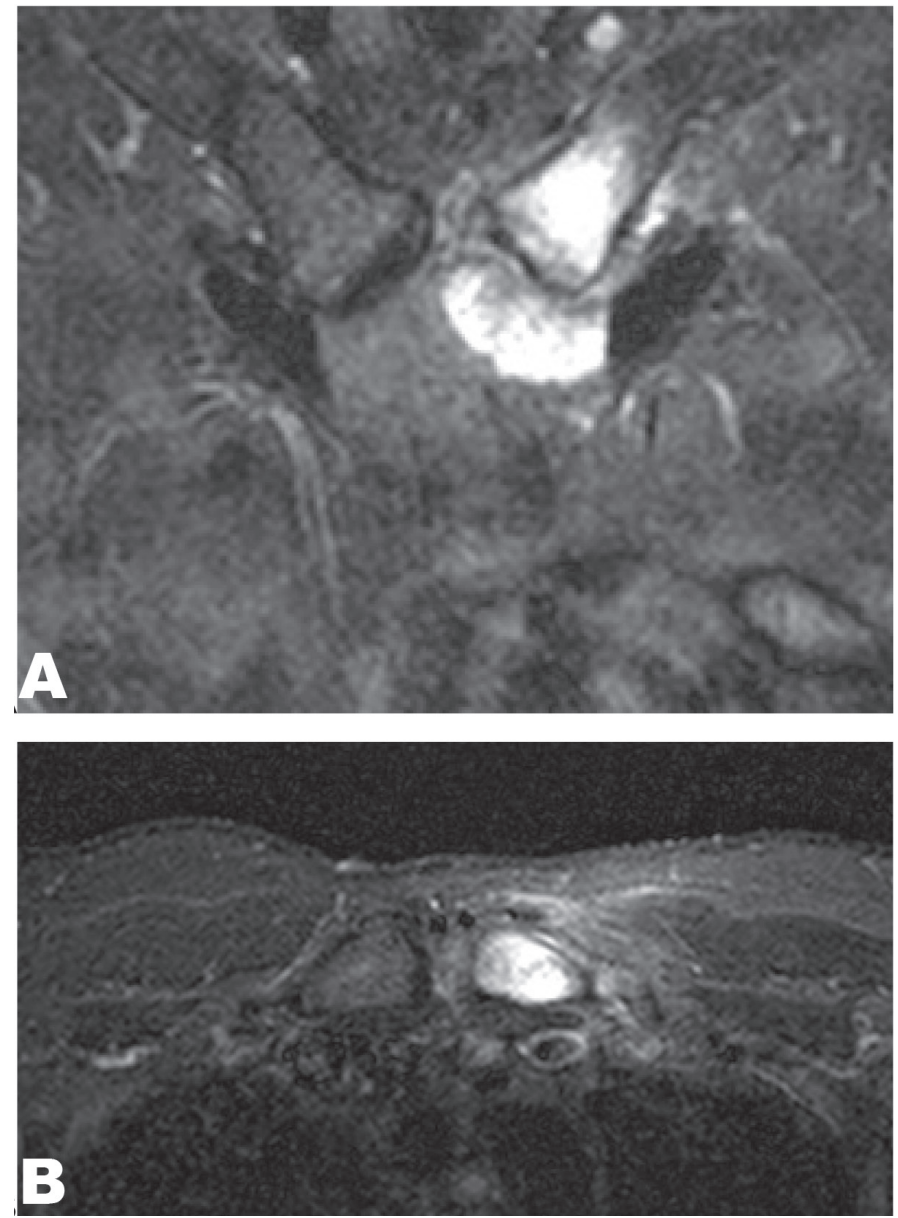

Figure 2: MR-STIR image of the sternoclavicular region showing bone marrow edema at the left side of the sternum as sign of arthritis (A) Coronal, (B) Transverse.

pustulosis aid the diagnosis of SAPHO syndrome. However, 32-60\% of patients develop bone and joint symptoms several years before skin symptoms, and $15 \%$ of patients do not develop skin symptoms [2]. Osteolytic changes are often noted at an earlier stage with or without osteosclerotic findings [2]. A computed tomography scan reveals an erosive change in the bone, and MR-STIR imaging shows an abnormally high signal in the bone. MR-STIR imaging can help differentiate active lesions from chronic ones [3].

\section{CONCLUSION}

Magnetic resonance imaging scan is useful in the diagnosis of sternoclavicular joint arthritis and especially magnetic resonance with the short-T1 inversion-recovery imaging can help differentiate active sternoclavicular joint arthritis from chronic one.

\section{How to cite this article}

Shikino K, Ikusaka M, Hirota Y. Magnetic resonance imaging of sternoclavicular joint arthritis due to SAPHO syndrome. Int $J$ Case Rep Images 2014;5(6):462-464.

doi:10.5348/ijcri-201459-CL-10047

$* * * * * * * * *$

\section{Author Contributions}

Kiyoshi Shikino - Substantial contributions to conception and design, Acquisition of data, Analysis and interpretation of data, Revising it critically for important intellectual content, Final approval of the version to be published

Masatomi IKusaka - Analysis and interpretation of data, Revising it critically for important intellectual content, Final approval of the version to be published

Yusuke Hirota - Analysis and interpretation of data, Revising it critically for important intellectual content, Final approval of the version to be published

\section{Guarantor}

The corresponding author is the guarantor of submission.

\section{Conflict of Interest}

Authors declare no conflict of interest.

\section{Copyright}

(C) 2014 Kiyoshi Shikino et al. This article is distributed under the terms of Creative Commons Attribution License which permits unrestricted use, distribution and reproduction in any medium provided the original author(s) and original publisher are properly credited. Please see the copyright policy on the journal website for more information.

\section{REFERENCES}

1. Guglielmi G, Scalzo G, Cascavilla A, Salaffi F, Grassi W. Imaging of the seronegative anterior chest wall (ACW) syndromes. Clin Rheumatol 2008;27(7):81521.

2. Nguyen MT, Borchers A, Selmi C, Naguwa SM, Cheema G, Gershwin ME. The SAPHO syndrome. Semin Arthritis Rheum 2012;42(3):254-65.

3. Earwaker JW, Cotten A. SAPHO: Syndrome or concept? Imaging findings. Skeletal Radiol 2003;32(6):311-27. 


\section{ABOUT THE AUTHORS}

Article citation: Shikino K, Ikusaka M, Hirota Y. Magnetic resonance imaging of sternoclavicular joint arthritis due to SAPHO syndrome. Int J Case Rep Images 2014;5(6):462-464.
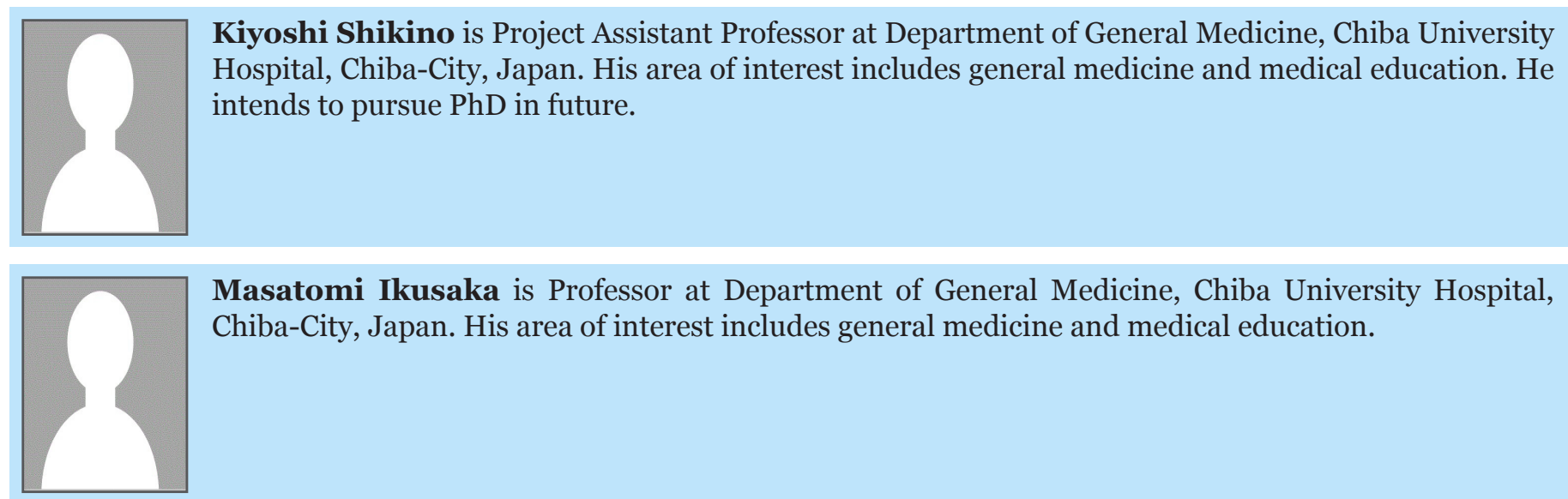

Masatomi Ikusaka is Professor at Department of General Medicine, Chiba University Hospital, Chiba-City, Japan. His area of interest includes general medicine and medical education.

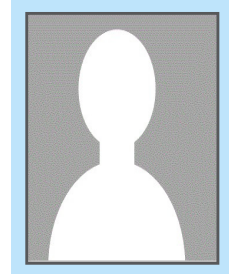

Yusuke Hirota is Clinical Fellow at Department of General Medicine, Chiba University Hospital, Chiba-City, Japan. His area of interest includes general medicine and medical education. He intends to pursue $\mathrm{PhD}$ in future.

Access full text article on other devices

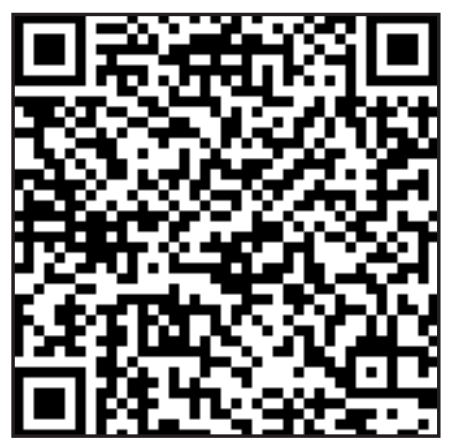

Access PDF of article on other devices

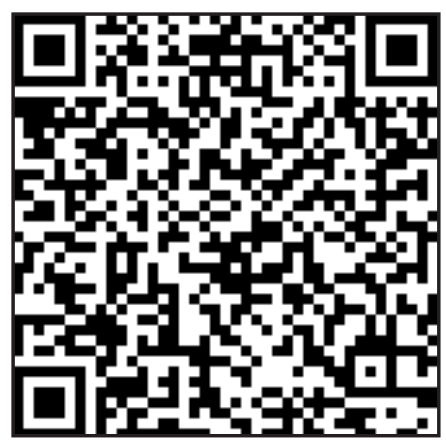

